\title{
Nazi characters in German propaganda and literature
}

http://dx.doi.ors/10.11606/1982-88372238236

Luis Krausz ${ }^{1}$

Resenha de: LORENZ, Dagmar. Nazi characters in German propaganda and literature. Leiden: Brill, 2018.

A ascensão da ideologia nazista no mundo de língua alemã deu-se ao longo de mais de 10 anos antes da efetiva ascensão de Adolf Hitler ao poder, em 1933. Desde o início da década de 1920, os conceitos sobre os quais se baseava o nazismo começaram a ganhar mais e mais espaço na consciência coletiva do mundo de língua alemã, arrebanhando um número crescente de defensores que, perplexos com a complexa e desastrosa situação econômica e social gerada pelas derrotas dos Império Alemão e Austro-Húngaro durante a Primeira Guerra Mundial, estavam em busca de novas ideias nacionais. Dentre esses conceitos, o mais importante é, sem dúvida, o de raça, segundo o qual diferentes grupos étnicos deveriam ser classificados, em bloco, em função de determinadas características fenotípicas, às quais corresponderiam, por sua vez, determinados genótipos e traços de caráter, entendidos como necessariamente mais ou menos virtuosos e favoráveis.

A eugenia e seu empenho pela "melhora" da raça estavam no epicentro da pseudociência, estabelecida por autores como Houston S. Chamberlain e Arthur de Gobineau, sobre a qual se assentava a política racial do nazismo. Aplicando ao ser humano conceitos provenientes do estudo dos animais, na pecuária, e do empenho na criação de raças melhores de cavalos, vacas e galinhas, a eugenia pressupõe a inutilidade da cultura e o poder absoluto da natureza. Supõe que, ao criar uma raça "boa", poderá dispensar a educação, entregando o homem a seus instintos, naturalmente bons,

\footnotetext{
${ }^{1}$ Universidade de São Paulo, Rua do Lago, 717, Cidade Universitária, Butantã, São Paulo, SP, 05508-900, Brasil. E-mail: lkrausz@ usp.br. ORCID: 0000-0002-1753-9470
}

\section{(cc) BY-NC}

Pandaemonium, São Paulo, v. 22, n. 38, set.-dez. 2019, p. 236-245 
Krausz, L. - Nazi characters in German Propaganda and Literature

transformando-o em mais um animal numa manada, entregando-o à sua "boa natureza" e exonerando-o do sentimento de responsabilidade por seus atos. Aliás, tais ideias encontrariam eco não só na Alemanha, mas em muitos outros países do Ocidente, dentre os quais o Brasil onde, sob o governo Vargas, imperavam, igualmente, ideias racistas, que justificaram o empenho do governo brasileiro no sentido da seleção entre candidatos à imigração, tendo em vista um esforço no sentido do "branqueamento" do país.

A Alemanha, combalida pela Primeira Guerra Mundial, e o velho Império Austrohúngaro, esfacelado em 1918, estavam, nas décadas de 1920 e 1930, em busca de novas identidades culturais e nacionais. Os ideais do humanismo oitocentista, que haviam fundamentado a concepção da Áustria como o centro de um império multi-étnico e multicultural, assim como a ideia humboldtiana de Bildung como o princípio básico da formação do homem moderno - e, portanto, do Estado moderno - passaram a recuar rapidamente ante o crescimento de uma visão nacional fundamentada em conceitos supostamente "naturais", como "povo" (Volk), "sangue" e "solo natal". Derivados da biologia, esses conceitos deterministas sustentavam a preponderância da natureza genética sobre a cultura, chocando-se, portanto, com os valores da "civilização", que haviam norteado o pensamento europeu do século XIX, criando as bases do pensamento liberal e da sociedade laica e burguesa.

Em todos os estratos das sociedades austríaca e alemã travou-se, durante o período entre-guerras, um intenso e acalorado debate, no qual se colocavam, de um lado, os defensores das ideias raciais e, de outro, aqueles que privilegiavam a cultura, o cultivo da interioridade e da sensibilidade, e a continuidade com a alta cultura alemã do período anterior à derrocada dos impérios alemão e austro-húngaro.

A República de Weimar e a Primeira República austríaca foram marcadas por uma grande tensão entre grupos que defendiam visões de mundo e ideologias opostas e que, com o passar do tempo, passaram a degenerar numa espiral ascendente de violência nunca antes vista no continente europeu. Como não poderia deixar de ser, esse conflito ideológico encontra-se presente, de forma proeminente, em boa parte da produção literária de língua alemã do período.

Observa-se que, após a derrocada no nazismo, em 1945, o mundo dos estudos germanísticos sistematicamente passou a ignorar a literatura na qual se discutiam e defendiam aquelas ideias que levaram ao estabelecimento do nacional-socialismo. A 
Krausz, L. - Nazi characters in German Propaganda and Literature

ideologia condenada e derrotada na Segunda Guerra Mundial tornou-se uma espécie de tabu e ainda hoje são bastante raros os trabalhos acadêmicos que sobre ela se debruçam.

Neste sentido, o livro Nazi characters in German propaganda and literature, de Dagmar G. G. Lorenz (2018) vem preencher uma lacuna importante nos estudos germanísticos, ao explorar o universo (pouco palatável, diga-se) daquela literatura de língua alemã que contribuiu, significativamente, no sentido de formar, elaborar e divulgar os valores fundantes do nazismo. Pois, como tantos outros movimentos políticos e como tantas outras ideologias, também o nazismo teve sua origem em livros, e por meio de livros conquistou parte significativa de seus aderentes e seguidores. Lorenz aborda, neste estudo, obras como Mein Kampf, de Adolf Hitler, Der Mythus des zwanzigsten Jahrhunderts, de Alfred Rosenberg, as memórias de Rudolf Höß, entre muitas outras. Ao mesmo tempo, justapõe a essas vozes outras, contrárias ao nazismo e à sua ideologia, dentre as quais as de escritores como Joseph Roth, Lion Feuchtwanger, Veza Canetti, Bertolt Brecht, Heinrich Böll e tantos mais.

É sempre a partir de uma perspectiva dupla, portanto, que Lorenz conduz o leitor em direção ao epicentro do debate ideológico que polarizou o mundo austro-alemão na primeira metade do século XX, com todos seus catastróficos e determinantes desdobramentos políticos, que determinariam o rumo da história do mundo de língua alemã nos séculos XX e XXI. E ela o faz com uma maestria que se revela, já à primeira vista, por meio das obras elencadas neste estudo sério, abrangente e inovador, dividido em três segmentos principais.

O primeiro desses segmentos diz respeito às origens e à conceptualização de personagens nazistas na literatura austro-alemã da década de 1920. Livros de apelo popular, que fazem a apologia das doutrinas raciais, como o romance antissemita Die Sünde wider das Blut, de Artur Dinter e a Rassenkunde des deutschen Volkes, de Hans Günther são contrapostos a romances e novelas como Die Stadt ohne Juden, de Hugo Bettauer, Das Spinnennetz, de Joseph Roth e Die jüdische Mutter, de Gertrud Kolmar.

Lorenz franqueia as fronteiras entre diferentes gêneros literários em busca daquelas imagens, símbolos e metáforas por meio das quais se buscava criar, entre os leitores, a persuasão em relação a determinadas ideias e posicionamentos políticos - ou por meio das quais se buscava, de maneira cada vez mais desesperada, expressar o protesto e a indignação ante a obliteração dos valores da Bildung, da civilização e mesmo

Pandaemonium, São Paulo, v. 22, n. 38, set.-dez. 2019, p. 236-245 
Krausz, L. - Nazi characters in German Propaganda and Literature

do processo de assimilação cultural que, até então, vinha orientando as relações dos judeus com o universo austro-alemão.

Trata-se, como demonstra Lorenz, de um conflito entre uma ideia de Alemanha como cultura e civilização, vinculada a um projeto de aprofundamento e de investigação pessoal, em contraposição a uma ideia de Alemanha como natureza, ligada ao triunfo de uma ideologia populista, que apela aos instintos, fundamenta-se na mimese e no eclipse da individualidade, e conduz o indivíduo à dissolução na massa, numa experiência quase mística, sob o jugo de um líder único e absoluto, responsável pelo destino da nação e de seu povo.

Esta entrega da individualidade aos poderes do sangue, da raça e de um líder supremo exerceu, como seria de se esperar, um apelo especialmente poderoso entre as camadas menos cultas e sofisticadas da população. O livro de Lorenz demonstra o teor popular da literatura de apologia ao nazismo, em contraposição a uma maior elaboração intelectual presente na literatura de protesto contra o nazismo. Assim, se a estética pequeno-burguesa predomina na vertente nazista, criada quase que exclusivamente por membros do partido, a literatura de protesto antifascista, obra de autores portadores de títulos universitários, representa valores intelectuais mais complexos e aponta, claramente, para a polaridade entre cultura e instinto, consciência e inconsciência, que está na raiz do embate entre o humanismo e o nazismo.

Lorenz aponta, igualmente, para a violência política que se espalhou pela Alemanha já a partir do fim da década de 1920, levando, cada vez mais, os escritores antifascistas a buscarem o exílio para preservarem sua integridade. Depois da ascensão de Hitler ao poder, estes passaram a ser impedidos de publicar e, ainda que houvesse editoras de língua alemã no exílio, como o famoso Querido Verlag, de Amsterdã, tornaram-se inacessíveis aos leitores alemães.

A segunda parte do livro focaliza o momento em que Hitler sobe ao poder, marcando uma virada no embate ideológico que vinha ocorrendo no campo literário até então, e abrindo, rapidamente, o caminho para a instauração de um regime totalitário na Alemanha e, posteriormente, na Áustria.

A imediata exclusão dos judeus dos quadros de todas as instituições públicas e a proibição de seu exercício de profissões relacionadas ao direito, à medicina e ao jornalismo, entre outras, desencadeia uma grande onda de exilados - e o exílio é o tema de um dos principais romances analisados por Lorenz neste segmento: Die Geschwister

Pandaemonium, São Paulo, v. 22, n. 38, set.-dez. 2019, p. 236-245 
Krausz, L. - Nazi characters in German Propaganda and Literature

Oppenheim, de Lion Feuchtwanger. Trata-se de uma saga familiar que aborda o destino dos Oppenheim, uma família de médicos, acadêmicos e empresários, típica do Bildungsbürgertum judaico berlinense, ante a tomada do poder pelos nazistas e a conseguinte expropriação de seus bens e exoneração dos cargos que ocupavam em diferentes instituições do Estado.

A família Oppenheim, conforme representada por Feuchtwanger, encarna as aspirações de aculturação e de integração na sociedade alemã nutridas pelos judeus emancipados do século XIX, que elegeram para si mesmos os valores da Bildung e do senso estético, das boas maneiras e dos bons relacionamentos, afastando-se, em seu estilo de vida e em suas ideias, dos judeus provenientes do Leste europeu, pouco familiarizados com os ambientes e com a cultura burguesa.

Como tantos outros de seu tempo, os Oppenheim são judeus que se consideravam, em primeiro lugar, alemães, encarando seu judaísmo apenas como uma questão de filiação religiosa. Julgavam que sua participação na Primeira Guerra Mundial lhes serviria como comprovação de seu pertencimento inconteste à nação alemã. Como escreve Feuchtwanger:

Sie haben am tiefsten an die deutsche Kultur geglaubt. Sie allein haben während des ganzen Krieges zu den Deutschen gehalten. 12.723 deutsche Juden sind in diesem Krieg gefallen, 2.2 Prozent aller deutschen Juden, viel mehr als der entsprechende Prozentsatz der Gesamtbevölkerung. (FEUCHTWANGER 1934: 121)

Iludidos com sua suposta condição de cidadãos plenos, eles julgam que tudo aquilo que dizia respeito aos judeus, nos discursos antissemitas, não dizia respeito a eles mesmos, e sim aos outros judeus, àqueles que não haviam descrito o percurso em direção à assimilação e à sociedade burguesa, e que, portanto, estaria em suas mãos decidir e escolher se eram ou não eram judeus. Como escreve Feuchtwanger em outra passagem deste romance: "Aber hat sich nicht die Mehrzahl der deutschen Juden so assimiliert, dass es wirklich nur von ihnen abhängt, ob sie sich für Juden erklären oder nicht?” (FEUCHTWANGER 1934: 34).

Feuchtwanger retrata, portanto, o colapso de uma mentalidade e de uma visão de mundo especificamente judaico-alemãs, que se tornaram anátema depois de 1933, transformando-se numa cultura de exílio, condenada ao declínio e ao desaparecimento. Indefesos ante a espoliação de seus bens e de seus lugares sociais pelos nazistas, que são representados como brutais, incultos e sádicos, eles se defrontam com o lugar nenhum do 
Krausz, L. - Nazi characters in German Propaganda and Literature

exílio e da perda de identidade, ao mesmo tempo em que se empenham em conservar ao menos resquícios de suas culturas e de seus hábitos em seus lugares de refúgio.

Em contraposição a este e outros romances, Lorenz aborda, também neste segundo segmento do livro, o filme de propaganda nazista Triumph des Willens, de Leni Riefenstahl, inteiramente baseado em imagens de multidões e de massas humanas, cujas aspirações são encarnadas por Hitler. Este, por sua vez, torna-se uma encarnação da própria nação, conforme sumariza, no filme, Rudolf Hess: "Die Partei ist Hitler, Hitler ist aber Deutschland wie Deutschland Hitler ist" (Triumph des Willens 1935). Com suas cenas repetitivas, com seu uso engenhoso de imagens e de música, com suas imagens fulgurantes, o filme possui um poder emocional primitivo, quase hipnótico, como convém a uma obra de arte destinada a fascinar e, portanto, dominar a mente de seus receptores.

A utopia nazista do renascimento nacional da Alemanha, o fim da Alemanha como uma sociedade civil, liberal e burguesa, é representado com um otimismo intoxicante e como uma solução para os problemas enfrentados por grande parte da população do país, e o filme tornou-se um enorme sucesso, inclusive para além das fronteiras germânicas: Triumph des Willens foi agraciado com importantes prêmios cinematográficos na França e na Itália e foi exibido com sucesso na Inglaterra.

A metodologia de Lorenz, como se vê, é dialética e sua argumentação se torna bem nítida por meio da justaposição de obras extraídas de dois universos culturais opostos que, a partir de 1933, passam a formar uma polaridade irresolvível: de um lado, o da cultura humanística; de outro, o da cultura völkisch, determinado a destruir a primeira. Se antes o embate entre estas duas visões de Estado se dava no interior da própria Alemanha, no contexto de uma disputa ideológica e de uma busca por persuasão e por poder político, a partir de 1933 a oposição ao nazismo passa a ser banida no contexto de um Estado totalitário, e logo exterminada, de maneira a abrir espaço para a ímpeto reconstrucionista e transformador de um regime que entendia a democracia como um empecilho no caminho supostamente glorioso que traçara para si mesmo.

Lorenz analisa, também, o romance Mephisto, de Klaus Mann, de 1936, uma incursão extraordinária na mentalidade nazista e no prazer masoquista de absoluta submissão da massa aos comandos do Führer. De fato, ao renunciar à reflexão e à responsabilidade sobre os próprios atos e sobre as próprias ideias, os aderentes do nazismo experimentavam um alívio psíquico, especialmente bem-vindo após os anos turbulentos, incertos e confusos da República de Weimar. O protagonista deste romance, 
Krausz, L. - Nazi characters in German Propaganda and Literature

Hendrik Höfgen, é um ator de segunda categoria que, sob o nazismo, se torna proeminente, porque os melhor qualificados deixaram o país. Klaus Mann, que era filho de Thomas Mann, deixara a Alemanha em 1933 com sua família, refugiando-se nos Estados Unidos. Emocionalmente instável, Höfgen torna-se um joguete nas mãos dos líderes nazistas. É um personagem fáustico, que se deixa conduzir por suas ambições desmesuradas. Tão oportunista e carreirista quanto medíocre, descreve uma trajetória que serve para denunciar a hipocrisia e a falsidade dos líderes nazistas com os quais se relaciona. Ao final, é desmascarado como um psicopata.

$\mathrm{Na}$ terceira parte do livro, Lorenz se volta sobre as representações de nazistas na literatura alemã pós-1945, uma nova fase que se inicia depois do colapso do Terceiro Reich, diante da necessidade de reorientação ideológica. As memórias de Rudolf Höß exemplificam, aqui, a recusa de um indivíduo em rever suas opiniões para ajustá-las à nova realidade, o que faz dele uma exceção entre uma série de autores que, tendo sido ligados ao nazismo, passam a tentar ocultar seu envolvimento com o regime derrotado.

O processo de desnazificação levado a cabo pelos aliados e o tribunal de Nürnberg constelam uma nova situação na Alemanha, que se vê obrigada a confrontar seu passado recente. E este confronto, conforme demonstra Lorenz, pode dar-se de duas maneiras: por meio da insistência na validade da ideologia nazista, mantida mais ou menos em segredo, dentro ou fora da nova Alemanha, ou por meio de uma revisão crítica de valores. Höß talvez seja o exemplo mais notório da primeira alternativa, como fica claro em sua autobiografia e em seus depoimentos diante do tribunal de Nürnberg, onde se empenhou, sempre, em demonstrar que cumpria, de forma exemplar, as ordens recebidas de seus superiores. Veterano da Primeira Guerra Mundial, e proto-nazista de primeira hora, que participara de um grupo de bandoleiros de extrema direita, comumente chamado de Freikorps, liderado por Gerhard Rossbach, já em 1919, ele se tornou uma figura paradigmática do "homem corporativo", dissociado de família, religião, intimidade e interioridade, e para quem o partido e os companheiros de armas se tornaram sucedâneos de um lar e um abrigo. Em seu livro de memórias, ele escreve: "Sempre me senti atraído pela camaradagem, na qual cada um pode confiar incondicionalmente no outro, diante do perigo e da necessidade" (apud SCHÖNPFLUG 2018: 155).

Se a exoneração da responsabilidade individual estava no cerne da entrega quase erótica dos membros do Volk alemão aos desígnios do Führer, isto também os eximia do dever da reflexão sobre os próprios atos. Tornando-se espécies de autômatos no 
Krausz, L. - Nazi characters in German Propaganda and Literature

cumprimento às ordens vindas seja da "boa natureza" (e daquilo que era entendido como tal), seja de lugares superiores de uma hierarquia que desembocava nas mãos do líder supremo, eles praticaram aquilo que Hannah Arendt denominou, ao testemunhar o julgamento de Adolf Eichmann, como "a banalidade do mal": os crimes mais hediondos eram justificados pelo simples fato de que foram cometidos em obediência a ordens e a princípios superiores. Revelam-se, assim, as consequências mais extremas da renúncia à individualidade, à reflexão e à responsabilidade, e da dissolução do indivíduo numa tropa ou manada, que fundamentavam, desde o princípio, a ideologia nazista.

As tendências à violência sendo legitimadas pelo Estado totalitário, os indivíduos a elas se entregam, frequentemente com deleite, substituindo a capacidade de pensamento crítico por um sentido de dever, que legitima o inadmissível. Este é um aspecto fundamental da mentalidade patológica do fascismo, que Höß exemplifica à perfeição.

Já o diário de Ingeborg Bachmann (Kriegstagebuch) exemplifica uma tendência oposta: filha de uma família austríaca de Klagenfurt que era simpática ao nazismo, seu livro revela a estreiteza de horizontes do ambiente pequeno-burguês no qual ela se formou. Bachmann envolveu-se, no pós-guerra, com um judeu austríaco exilado na Inglaterra que, durante a guerra, combatera nas fileiras do exército britânico, e que, aos poucos, vai informando-a a respeito da realidade dos campos de extermínio, até então eclipsada. Este judeu leva-a a afastar-se de Klagenfurt e da carga insuportável do passado nazista de sua família, ao mesmo tempo em que dá início a um processo de reelaboração do passado e de uma busca por novas perspectivas, característico da realidade do pósguerra na Áustria e na Alemanha.

A tentativa de reelaborar (e também de obliterar) o passado é detectada por Lorenz em obras de Heinrich Böll e Günther Grass. Böll, um veterano da Segunda Guerra Mundial, investiga a mentalidade dos soldados nazistas à época da derrota alemã no romance Der Zug war pünktlich, retratando recrutas que são jovens demais para os cargos que ocupam. Em sua revisão do nazismo, o empenho de Böll dá-se no sentido de traçar uma distinção entre os oficiais dos escalões superiores, identificados com o Partido Nazista, e os simples recrutas, presumidamente ingênuos e inocentes. O livro, cujo título original era Zwischen Lemberg und Czernowitz, está ambientado no epicentro do genocídio, na antiga Galícia e Bucovina austro-húngaras, e tem como protagonista um soldado raso alemão que é, também, um católico devoto, que reza pelos judeus que estão sendo exterminados. Ao mesmo tempo, a inevitabilidade da derrota dos alemães torna-se 
Krausz, L. - Nazi characters in German Propaganda and Literature

cada vez mais clara para o protagonista ao longo da narrativa, e a moral de suas tropas se esfacela, sustentada apenas por um sentimentalismo barato e ilusório.

Um dos aspectos importantes explorados por Böll neste romance é a perda de identidade pessoal no contexto da mentalidade militarista do nazismo, onde o indivíduo sucumbe inteiramente à mecânica da dominação e submissão. Ao mesmo tempo, a própria desmoralização dos soldados parece associada, na narrativa, à participação no genocídio: Böll cita os discursos de soldados psicologicamente destruídos depois de cometerem assassinatos em massa.

A análise do romance Die größere Hoffnung, de Ilse Aichinger, encerra este volume e reflete acerca da dissolução da assim chamada "simbiose judaico-alemã" (que foi, sobretudo, a absorção, por parte dos judeus, da cultura alemã, mas sem sua contrapartida). As políticas nazistas impuseram a segregação não só entre dois universos culturais antes em diálogo, mas também entre membros de famílias, inclusive de famílias nucleares, que foram dissolvidas em decorrência das leis raciais, num mundo onde o destino passou a ser determinado exclusivamente pela ancestralidade.

Em sua investigação acerca das representações de nazistas, Lorenz desmascara como uma grande farsa o discurso da supremacia racial, por meio do qual o indivíduo é reduzido a uma condição sub-humana, ao submeter-se aos imperativos do sangue, do instinto, da nação e de seu líder supremo, abdicando de sua autonomia, de seu livrearbítrio, de sua capacidade de julgar e de discernir e, portanto, da própria humanidade.

Desde o seu surgimento na década de 1920, personagens nazistas despertavam a imaginação cultural alemã, em termos positivos tanto quanto negativos. Durante o pósguerra, novas disputas a respeito do nazismo foram desencadeadas no contexto da Guerra Fria e da divisão da Alemanha em duas repúblicas. Hoje, quando os participantes do nazismo já se tornaram figuras do passado, novas constelações imaginárias surgem à sua volta, em projetos de revisionismo histórico.

O livro de Lorenz, assim, tem a grande virtude de explorar um universo pouco conhecido e de revelar, por meio da literatura, não só o embate ideológico que foi travado no mundo de língua alemã no período entre-guerras, mas também a própria mecânica da ideologia nazista e, portanto, os motivos pelos quais ela se tornaria tão sedutora e atraente no contexto posterior à destruição do Império Alemão e do Império Austro-húngaro. Os laços entre literatura e política e as influências mútuas que exercem, uma sobre a outra, a literatura e a política, transparecem de maneira especialmente nítida ao longo deste 
Krausz, L. - Nazi characters in German Propaganda and Literature

estudo, que é também uma reflexão sobre o funcionamento das sociedades humanas e um olhar iluminador sobre a mecânica do totalitarismo. As reflexões de caráter teórico estão praticamente ausentes desse estudo, que se baseia, sobretudo, na justaposição de análises de romances que pertencem a um e outro dos campos constelados pelo debate ideológico que polarizou o mundo de língua alemã durante o entre-guerras. Esta poderia ser uma crítica ao livro, que talvez pudesse beneficiar-se de conclusões fundamentadas em conceitos estabelecidos por estudiosos como Theodor Adorno, Hannah Arendt, Zygmunt Baumann e outros tantos que se debruçaram sobre os totalitarismos do século XX. Porém, a leitura das análises de obras literárias elencadas pela autora gentilmente conduz o leitor a uma série de conclusões próprias a respeito da origem e do triunfo do nazismo, de tal maneira que aquilo que poderia parecer uma lacuna acaba por tornar-se uma virtude.

Ante o panorama político atual, o livro de Lorenz ganha uma inesperada e importante atualidade, e funciona como uma advertência sólida e consistente para os grandes perigos decorrentes da letargia moral, da passividade e da silenciosa cumplicidade que têm acompanhado, em diferentes partes do mundo, a desastrosa ascensão de forças políticas que recrutam seus seguidores com base na inconsciência, na complacência e na concessão de vantagens momentâneas.

\section{Referências bibliográficas}

Feuchtwanger, Lion. Die Geschwister Oppenheim. Amsterdam: Querido Verlag, 1934.

LORENZ, Dagmar. Nazi characters in German propaganda and literature. Leiden: Brill, 2018. $186 \mathrm{p}$.

SCHÖNPFlug, Daniel. A era do cometa. São Paulo: Todavia, 2018.

Triumph des Willens. Produção de Leni Riefenstahl. Berlin: Universum Film AG, 1935 (114 min). 